\title{
Mapping Brain Metabolic Connectivity in Awake Rats with $\mu$ PET and Optogenetic Stimulation
}

\author{
Panayotis K. Thanos, ${ }^{1,2,3}$ Lisa Robison, ${ }^{1,3}$ Eric J. Nestler, ${ }^{5}$ Ronald Kim, ${ }^{1,2}$ Michael Michaelides, ${ }^{5}$ Mary-Kay Lobo, ${ }^{4}$ \\ and Nora D. Volkow ${ }^{1}$ \\ ${ }^{1}$ Laboratory of Neuroimaging, National Institute on Alcohol Abuse and Alcoholism, National Institutes of Health, Rockville, Maryland 20852, ${ }^{2 B e h a v i o r a l ~}$ \\ Neuropharmacology and Neuroimaging Laboratory, Medical Department, Brookhaven National Laboratory, Upton, New York 11973, ${ }^{3}$ Department of \\ Psychology, Stony Brook University, Stony Brook New York 11794, ${ }^{4}$ Department of Anatomy and Neurobiology, University of Maryland School of Medicine, \\ Baltimore, Maryland 21201, and 5Department of Neuroscience, Mount Sinai School of Medicine, New York, New York 10029
}

Positron emission tomography (PET) with $\left[{ }^{18} \mathrm{~F}\right] 2$-fluoro-2-deoxy-D-glucose was used to measure changes in regional brain glucose metabolism (BGluM) in response to optogenetic stimulation (using the excitatory channelrhodopsin-2) of the nucleus accumbens (NAc) in awake rats. We demonstrated not only increases in BGluM that correlated with c-Fos expression in the region of stimulation, but also BGluM increases in the ipsilateral striatum, periaqueductal gray, and somatosensory cortex, and in contralateral amygdala, ventral pallidum, globus pallidus, and hippocampus, as well as decreases in BGluM in regions of the default mode network (retrosplenial cortex and cingulate gyrus) and secondary motor cortex. Additional exploration of c-Fos expression in regions found to be activated by PET results found corroborating evidence, with increased c-Fos expression in the ipsilateral somatosensory cortex, contralateral amygdala and globus pallidus, and bilateral periaqueductal gray. These findings are consistent with optogenetic excitation of the area of stimulation (NAc), as well as with stimulatory and inhibitory effects on downstream regions. They also confirm the utility of PET imaging to monitor connectivity in the awake rodent brain.

\section{Introduction}

The development of optogenetic tools to selectively activate or inhibit particular brain regions or cells types has allowed researchers to map the function of specific neuronal circuits in the rodent brain (Boyden et al., 2005; Cardin et al., 2010; Zhang et al., 2010; Lee, 2012). One approach is based on the use of the excitatory channelrhodopsin-2 (ChR2), a cation channel that is activated when exposed to blue light at $\sim 470$ nm (Boyden et al., 2005; Cardin et al., 2010; Zhang et al., 2010; Lee, 2012). More recently, the combined use of optogenetic and functional magnetic resonance imaging (fMRI) has been used to investigate functional connectivity in the rodent brain (Lee et al., 2010; Kahn et al., 2011; Lee, 2011, 2012). These fMRI studies, however, are limited by the use of anesthesia, which affects neuronal activity and the strength of blood oxygen level-dependent (BOLD) signals measured by fMRI (Stover et al., 2004; Heinke and Koelsch, 2005; Qiu et al., 2008; Tsurugizawa et al., 2010).

\footnotetext{
Received Oct. 25, 2012; revised Dec. 23, 2012; accepted Feb. 18, 2013.

Author contributions: P.K.T. designed research; L.R., R.K., and M.-K.L. performed research; M.M. contributed unpublished reagents/analytic tools; P.K.T., L.R., and M.-K.L. analyzed data; P.K.T., E.J.N., M.-K.L., and N.D.V. wrote the paper.

This work was supported by the intramural program at NIAAA and Grants AA11034, AA07574, AA07611, and DA08227. We thank Javier Gonzalez-Garzon, Manuel Desco, and Mala Ananth for helpful suggestions with the SPM. The authors declare no competing financial interests.

Correspondence should be addressed to either of the following: Mary Kay Lobo, University of Maryland School of Medicine, 20 Penn Street HSFII S251, Baltimore, MD 21201, E-mail: mklobo@umaryland.edu; or Dr. Nora D. Volkow, 6000 Executive Blvd \# 402, Rockville, MD 20852, E-mail: nvolkow@nida.nih.gov.

DOI:10.1523/JNEUROSCI.4997-12.2013

Copyright $\odot 2013$ the authors $\quad 0270-6474 / 13 / 336343-07 \$ 15.00 / 0$
}

Brain imaging with positron emission tomography (PET) has been extensively used with $\left[{ }^{18} \mathrm{~F}\right] 2$-fluoro-2-deoxy-D-glucose (FDG) to measure regional brain glucose metabolism, which serves as a marker of brain activity, both in humans and laboratory animals (Volkow et al., 2009, 2011; Wang et al., 2009; Apostolova et al., $2010)$. Access to high-resolution PET scanners ( $\mu$ PET) has facilitated their use for assessing brain glucose metabolism in vivo in rodents (Rice et al., 2006; Thanos et al., 2008a; Sobrado et al., 2011; Michaelides et al., 2012). Glucose metabolism, as measured with PET-FDG, reflects brain activity occurring during the uptake period of FDG (first 30-35 min after radiotracer injection), after which the activity is trapped in the brain and remains stable for at least $60 \mathrm{~min}$; and it is during this period that scanning is performed. Since animals are anesthetized after the uptake of FDG by the brain is complete, this allows researchers to measure brain metabolism in awake animals noninvasively.

The present study used $\mu$ PET with FDG to measure optogenetic stimulation (OGS) of the nucleus accumbens (NAc), a major brain reward region, using ChR2. We tested the hypothesis that excitation of the NAc by OGS would result in increased metabolism in the region of stimulation and in cortical (frontal cortex) and subcortical [striatum, globus pallidus (GP), and subthalamic nucleus] projections. In parallel, we mapped c-Fos expression to corroborate regional activation by OGS. We show increases in glucose metabolism in the NAc that correlate with c-Fos expression, and in downstream projections regions, which is corroborated by c-Fos immunolabeling data. We also found that stimulation of the NAc decreased activity in regions from the default mode network (DMN). This demonstrates the feasibility 


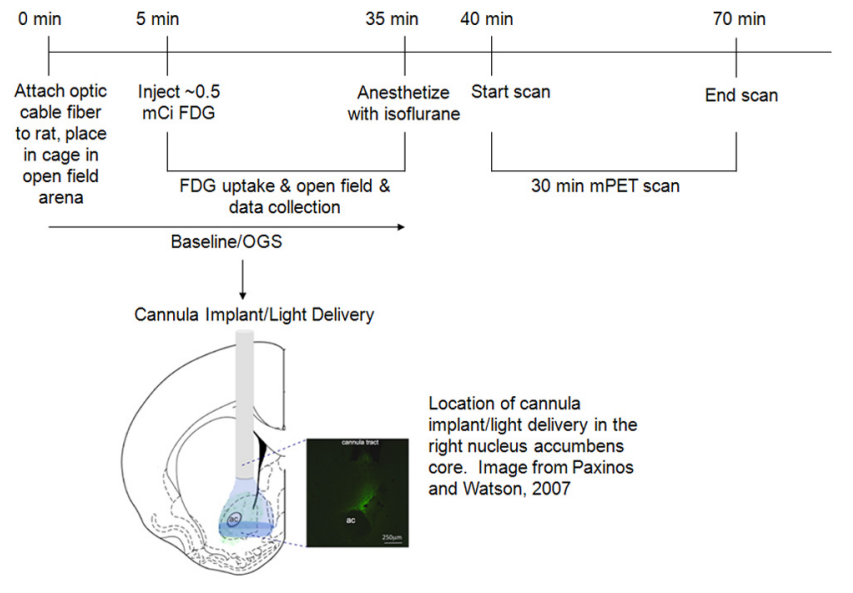

Figure 1. FDG scanning protocol.

of using $\mu$ PET with FDG in conjunction with OGS to map connectivity in the awake rat brain.

\section{Materials and Methods}

Animals

Male Sprague Dawley rats (Charles River) were housed under standard laboratory conditions $\left(22.0 \pm 2^{\circ} \mathrm{C}, 12 \mathrm{~h}\right.$ reverse light/dark cycle). Food and water were available ad libitum except for the night before $\mu \mathrm{PET}$ scans, during which subjects were food-deprived for $12 \mathrm{~h}$ to attain consistency in blood glucose levels as abnormal blood glucose levels interfere with FDG uptake (Fueger et al., 2006; Wong et al., 2011). The experiment was conducted in accordance with the Guide for the Care and Use of Laboratory Animals (1996) and approved by the Brookhaven National Laboratory Institutional Animal Care and Use Committee.

\section{Stereotaxic surgery}

At age 8-10 weeks, rats were anesthetized with ketamine $(75 \mathrm{mg} / \mathrm{kg})$ and xylazine $(6.7 \mathrm{mg} / \mathrm{kg})$, placed in a small-animal stereotaxic headholder, and their skull was exposed. One milliliter of adeno-associated virus serotype 2 (AAV2)-hsyn-ChR2-EYFP (vector obtained from Karl Deisseroth, Stanford University, Stanford, CA) ( $n=8$ /group) or AAV2-GFP control virus ( $n=9$ /group) was infused into the NAc core in the right hemisphere (AP +1.7, $\mathrm{ML}+1.5, \mathrm{DV}-6.5$ from bregma) at a rate of 0.1 $\mu \mathrm{l} / \mathrm{min}$. A 20 gauge cannula, $6 \mathrm{~mm}$ in length from the cannula base, was placed into the right NAc ( $\mathrm{AP}+1.7, \mathrm{ML}+1.5, \mathrm{DV}-6.0$ from bregma). Instant adhesive was placed between the cannula base and the skull, micro-screws were placed around the skull, and dental cement was used to secure the cannula to the skull. Rats recovered for a minimum of 2 weeks while waiting for optimal AAV expression.

\section{In vivo imaging}

FDG scanning protocol. Each rat was scanned twice, one week apart (counterbalanced design): once at baseline (optical fiber attached but no stimulation applied) and once following OGS (Fig. 1). Rats were connected to the optical fiber and placed in a small Plexiglas cage (dimensions $19.1 \mathrm{~cm} \times 29.2 \mathrm{~cm} \times 12.7 \mathrm{~cm}$; Ancare) to restrict movement and minimize regional brain activation from motor behavior. All animals were previously habituated to this cage for three sessions. After placement in the small cage, blue $(473 \mathrm{~nm})$ light stimulation, pulsed at $10 \mathrm{~Hz}$, was applied through the optical fiber at $30 \mathrm{~s}$ intervals ( $30 \mathrm{~s}$ on/30 s off) for 5 min (light turned off for the baseline scan). Blue light was calculated to target $\sim 900 \mu \mathrm{m}$ tissue depth from the optic fiber tip with a tissue irradiance of $\sim 35$ $\mathrm{mW} / \mathrm{mm}^{2}$ at the tip using the online predicted irradiance calculator (http://www.stanford.edu/group/dlab/cgi-bin/graph/chart.php).

Figure 1 shows the location of cannula and light delivery, with relevant projections to and from the NAc. Rats were then injected intraperitoneally with $\sim 0.5 \mathrm{mCi}$ of FDG. FDG was purchased from a commercially available radiopharmaceutical supplier (Cardinal Health). Each rat was awake for the $30 \mathrm{~min}$ period of FDG uptake, during which time the blue light was applied through the optical fiber at the same frequency and time intervals as before (light turned off for the baseline scan). During the uptake period, a photobeam activity monitoring system (dimensions $40.64 \mathrm{~cm} \times 40.64 \mathrm{~cm} \times 40.64 \mathrm{~cm}$; TruScan, Coulbourn Instruments) measured locomotor activity (floor plane distance traveled) in the cage. Rats were previously habituated to being transported to the $\mu$ PET facility, connected to the optical fiber, and to the Plexiglas "uptake" cage for $30 \mathrm{~min}$ for $3 \mathrm{~d}$ before testing. During these habituation trials, locomotor activity also was measured.

$\mu P E T$ image acquisition. Following the uptake period, rats were anesthetized with isoflurane (1.5-2.0\%) and placed in a prone position on the $\mu$ PET scanner. An R4 $\mu$ PET tomograph (Concorde CTI, Siemens), which has a transaxial resolution of $2.0 \mathrm{~mm}$ full-width at half maximum, with a field-of-view (FOV) of $11.5 \mathrm{~cm}$ was used for imaging. Animals were placed in the center of the FOV and dynamic scans were taken for 30 min (21 frames: 6 frames, $10 \mathrm{~s} ; 3$ frames, $20 \mathrm{~s} ; 8$ frames, $60 \mathrm{~s} ; 4$ frames, $300 \mathrm{~s})$ and then averaged. After scanning, images were corrected for photon emission and reconstructed using the OSEM3D/MAP algorithm provided by Concorde CTI.

\section{$\mu P E T$ image analysis}

Statistical parametric mapping analysis. Statistical parametric mapping (SPM) image processing was completed using PMOD v.2.75 software (PMOD Technologies Ltd.), and the averaged FDG images (across all dynamic acquisitions) were coregistered to the Schweinhardt atlas in Paxinos coordinates. Images were classified into four datasets: GFP baseline, GFP stimulation, ChR2 baseline, and ChR2 stimulation. Images were smoothed ( $4 \mathrm{~mm}$ Gaussian), then spatially normalized to a $\mu$ PET reference image (manually selected by the user), as previously described (Thanos et al., 2008b; Pascau et al., 2009). Images were analyzed using the SPM8 software package. Regional metabolic changes for each animal were assessed relative to its global activity to normalize for injected dose and weight differences between animals, with intensity normalization to the mean by the proportional scaling method. A paired $t$ test was performed for each group (GFP and ChR2) comparing regional brain glucose metabolism between the baseline and the stimulation scans. After estimation of the statistical model, $t$ contrasts were applied to reveal the effects of interest. An uncorrected $p$-value of $<0.005$ and a cluster $K_{\mathrm{e}}>$ 100 were used as threshold to determine statistical significance. To minimize the likelihood of false positives, we set the threshold for significance to $T=5.7$, which was the maximum $T$ value obtained for the comparisons in the GFP rats (baseline vs stimulation), which we used as an estimate for random significant events.

NAc cluster analysis (region of interest method). To quantify changes in brain glucose metabolism in the NAc following OGS, PMOD software (v.2.75, PMOD Technologies Ltd.) was used to manually draw a region of interest (ROI) in the location of the NAc cluster (at given SPM coordinates) that was significantly activated in the ChR2 group. Activity in this ROI was measured both for the baseline and stimulation condition for the GFP and ChR2 rats, and was normalized to the activity in the whole brain (NAc ROI activity/whole-brain activity).

\section{Immunohistochemistry}

Perfusion and sectioning. One week after the $\mu$ PET imaging experiment, rats (GFP, $n=4$; ChR2, $n=6$ ) were again stimulated with blue $(473 \mathrm{~nm})$ light, pulsed at $10 \mathrm{~Hz}$, applied through the optical fiber at $30 \mathrm{~s}$ intervals (30 s on/30 s off) for $10 \mathrm{~min}$. Ninety minutes after stimulation (to allow for maximum c-Fos expression), rats were anesthetized with 100/10 $\mathrm{mg} / \mathrm{kg}$ ketamine/xylazine, i.p. and were then perfused with $0.9 \%$ saline solution followed by $4 \%$ paraformaldehyde (PFA) in $0.2 \mathrm{M}$ PBS. Perfusions were performed using the Perfusion One Sacrifice Perfusion System (NeuroLab). Brains were postfixed overnight in $4 \%$ PFA in $0.2 \mathrm{M}$ PBS and then cryoprotected in 30\% sucrose in PBS. Brains were mounted using Tissue-Tek O.C.T. compound embedding medium and rapidly frozen in dry ice for cryosectioning. The brains were cryosectioned (Leica CM3050S) at $40 \mu \mathrm{m}$ and stored in PBS with $0.01 \%$ Azide.

c-Fos immunolabeling, imaging, and analysis. Brain sections were rinsed in PBS and subsequently blocked for $30 \mathrm{~min}$ in 3\% Normal Donkey Serum and $0.3 \%$ Triton-X in PBS. Tissue sections were incubated 
Table 1. SPM-derived stereotaxic coordinates of clusters with significant differences between baseline and stimulation scans in the ChR2 group ( $p<0.005$; $\left.K_{e}>100\right)$

\begin{tabular}{|c|c|c|c|c|c|c|c|c|}
\hline & \multirow[b]{2}{*}{ Brain structure(s) } & \multirow[b]{2}{*}{$K_{\mathrm{e}}$} & \multirow[b]{2}{*}{$T$} & \multirow[b]{2}{*}{ Z-score } & \multirow[b]{2}{*}{$p$ level } & \multicolumn{3}{|c|}{$\begin{array}{l}\text { Stereotaxic } \\
\text { location of peak } \\
(\mathrm{mm})\end{array}$} \\
\hline & & & & & & $x$ & $y$ & $Z$ \\
\hline \multirow{6}{*}{$\begin{array}{l}\text { Stimulation }>\text { Baseline } \\
\quad \text { (Activation) }\end{array}$} & $\mathrm{dHP} / \mathrm{st}$ & 136 & 10.95 & 4.38 & 0.000 & -47 & 46 & -35 \\
\hline & $\mathrm{S} 2$ & 170 & 7.96 & 3.91 & 0.000 & 57 & 64 & -11 \\
\hline & $\mathrm{CPu}$ & & 6.61 & 3.61 & 0.000 & 41 & 60 & -5 \\
\hline & VP/GP/Amygdala & 264 & 6.54 & 3.60 & 0.000 & -29 & 78 & -13 \\
\hline & PAG & 188 & 6.44 & 3.57 & 0.000 & 1 & 58 & -51 \\
\hline & NAC & 102 & 5.76 & 3.39 & 0.000 & 19 & 74 & 15 \\
\hline \multirow{2}{*}{$\begin{array}{l}\text { Stimulation }<\text { Baseline } \\
\text { (Inhibition) }\end{array}$} & RSA & 168 & 8.92 & 4.08 & 0.000 & 3 & 14 & -35 \\
\hline & $\mathrm{Cg} 1 / \mathrm{M} 2$ & 255 & 7.94 & 3.90 & 0.000 & 1 & 10 & -5 \\
\hline
\end{tabular}

$\mathrm{dHP}$, Dorsal hippocampus; st, stria terminalis; $\mathrm{S}$, secondary somatosensory cortex; $\mathrm{CPu}$, caudate-putamen; VP, ventral pallidum; GP, globus pallidus; RSA, retrosplenial cortex; $C g 1$, cingulate gyrus, area 1; M2, secondary motor cortex.

overnight at room temperature in the above blocking solution containing chicken anti-GFP (1:8000, catalog \#GFP-1020, Aves Labs) for EYFP or GFP detection and rabbit anti-c-Fos (1:1000, catalog \#sc-52, Santa Cruz Biotechnology) for c-Fos detection. On the second day, tissue sections were rinsed in PBS, followed by a $1 \mathrm{~h}$ incubation in secondary antibodies: Donkey anti-Chicken-Dylight-488 and Donkey anti-rabbitCy3 (both at 1:500, Jackson Immunoresearch) in PBS. The tissue was then rinsed in PBS before mounting onto Superfrost Plus slides. Sections were dehydrated in a graded ethanol series and Citrosolve, and then coverslipped with mounting media.

Immunofluorescence was imaged on an Olympus Bx61 confocal microscope. c-Fos-positive cells were counted in the region of the virus infection directly beneath the cannula-optic fiber, as well as in the secondary somatosensory cortex, amygdala, globus pallidus, and periaqueductal gray (PAG). Total c-Fos cell number was quantified from two 636 $\mu \mathrm{m} \times 636 \mu \mathrm{m}$ images from each subject using ImageJ software (NIH).

\section{Statistical analysis}

A two-way repeated-measures ANOVA (between-subjects factor: Group; within-subjects factor: Time) was used to assess locomotor activity during the habituation and the baseline and stimulation sessions. A two-way repeated measures ANOVA (between-subjects factor: Group; within-subjects factor: Intervention) was used to assess brain glucose metabolism in the ROI encompassing the NAc cluster during baseline and stimulation scans. A one-way ANOVA (between-subjects factor: Group) was used to compare c-Fos expression in the NAc induced by OGS in GFP and ChR2 rats. A two-way ANOVA (between-subjects factors: Group and Hemisphere) was used to compare c-Fos expression induced by OGS in the remaining brain regions in GFP and ChR2 rats. ANOVAs were followed by post hoc tests (Holm-Sidak method) where appropriate. Pearson product correlations were used to assess the relationship between the changes in glucose metabolism and the changes in c-Fos expression in the NAc. Statistical significance was set at $p<0.05$ and statistical tests were performed using SigmaStat v11.0 software.

\section{Results}

\section{Brain glucose utilization in response to OGS of the NAc}

Statistical parametric mapping

Brain metabolic differences between baseline and OGS stimulation were determined both for activation (stimulation $>$ baseline) and inhibition (stimulation $<$ baseline). To assess significance in the ChR2 group we initially set the statistical threshold to $p<0.005$ (cluster $K_{\mathrm{e}}>100$ ) and then reset for the threshold corresponding to the maximum $T$ value in the GFP group $(T=5.7)$, which we used as estimate of randomness. Based on these criteria, OGS in the ChR2 group resulted in five activated and two inhibited clusters (Table 1, Fig. 2). One of the activated clusters was located in the core of the NAc where the cannula was placed for light stim- ulation. The other four clusters that showed significant increases encompassed (1) dorsal hippocampus and stria terminalis; (2) caudate/putamen and adjoining somatosensory cortex; (3) globus pallidus, ventral pallidum, and amygdala; and (4) periaqueductal gray. The two clusters showing decreases encompassed (1) retrosplenial cortex (from -3.2 to $-4.2 \mathrm{~mm} \mathrm{AP}$ ); and (2) anterior cingulate gyrus (from 0 to $-1.8 \mathrm{~mm} \mathrm{AP}$ ) and secondary motor cortex.

\section{Effects in NAc (ROI method)}

The effect of OGS at the site of stimulation was further explored by measuring the individual metabolic values (normalized to whole brain) in the region in the NAc where differences between the baseline and stimulation scans were observed (Fig. 3A). Each rat in the ChR2 group had a positive response (increased activation) between the baseline and stimulation scans, suggesting a consistent stimulation and activation near the site of OGS, while this was not the case for GFP rats. The two-way repeatedmeasures ANOVA showed a significant interaction between group and intervention $\left(F_{(1,15)}=9.332, p=0.008\right)$. Pairwise comparisons revealed that only ChR2 rats showed a significant increase $(16 \pm 3 \%)$ in brain glucose metabolism in the NAc from baseline to stimulation scans $(p=0.004)$. Additionally, during the stimulation scan, NAc metabolism was significantly greater $(13 \%)$ in the ChR2 than in the GFP group $(p=0.005)$.

\section{c-Fos expression}

c-Fos expression in the NAc was compared between GFP and ChR2 rats following OGS (Fig. 4). ChR2 rats exhibited increased c-Fos expression compared with GFP rats $\left(F_{(1,8)}=\right.$ 20.392; $p=0.002)$. The changes in brain glucose metabolism in the NAc between baseline and stimulation and c-Fos expression across both groups (all animals) were significantly correlated ( $r=$ 0.7721, $p=0.009$; Fig. 3B). Similarly, in ChR2 rats we found induction of c-Fos in four brain regions within clusters found to be activated in the SPM PET results (Fig. 5). ChR2 rats displayed increased c-Fos immunoreactivity in S2 (secondary somatosensory cortex), ipsilateral to the ChR2 site, $\left(F_{(1,18)}=17.26\right.$ (Interaction), 18.37 (Group), and 36.84 (Hemisphere), $p<0.0001)$ ). The amygdala and GP, contralateral to the ChR2 site, both displayed increased c-Fos in ChR2 rats (Amygdala, $F_{(1,18)}=10.11$ (Interaction), $p<0.01$ ); GP, $F_{(1,18)}=4.89$ (Interaction), 26.35 (Group), $p<0.001)$ ). Finally, both PAG hemispheres, in ChR2 rats, displayed an enhanced induction of c-Fos $\left(F_{(1,18)}=43.40\right.$ (Group), $p<0.001$ for ipsilateral and $p<0.01$ for contralateral)).

\section{Locomotor activity}

There were no significant differences in locomotor activity between the groups (ChR2, GFP) $\left(F_{(1,14)}=2.658, p=0.125\right)$, nor was there a significant group $\times$ time interaction effect $\left(F_{(4,56)}=\right.$ $0.603, p=0.662)$ (Fig. 6). There was only a significant main effect of time $\left(F_{(4,56)}=5.188, p=0.001\right)$; as expected, rats were more active during the habituation sessions compared with the sessions when the $\mu$ PET scans were performed.

\section{Discussion}

Here, we show that OGS of the NAc using ChR2 increased c-Fos expression and glucose metabolism in the region of stimulation. Additionally, we observed increased metabolism in regions interconnected with the NAc, including the basal ganglia (caudateputamen, globus pallidus, and ventral pallidum) and limbic regions (amygdala, hippocampus) and decreased metabolism in 

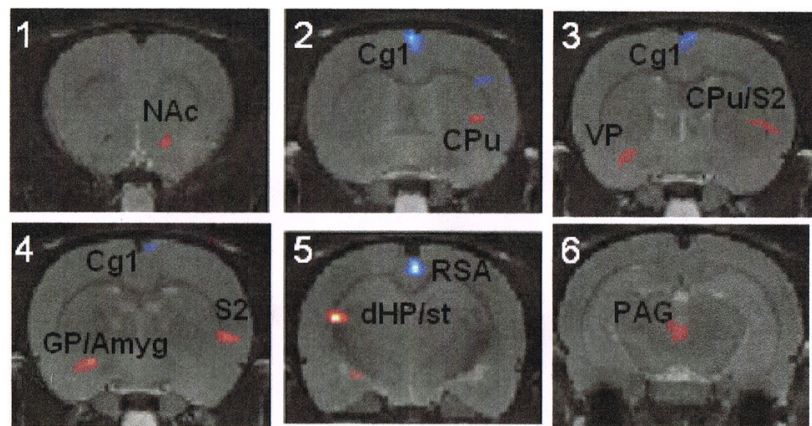
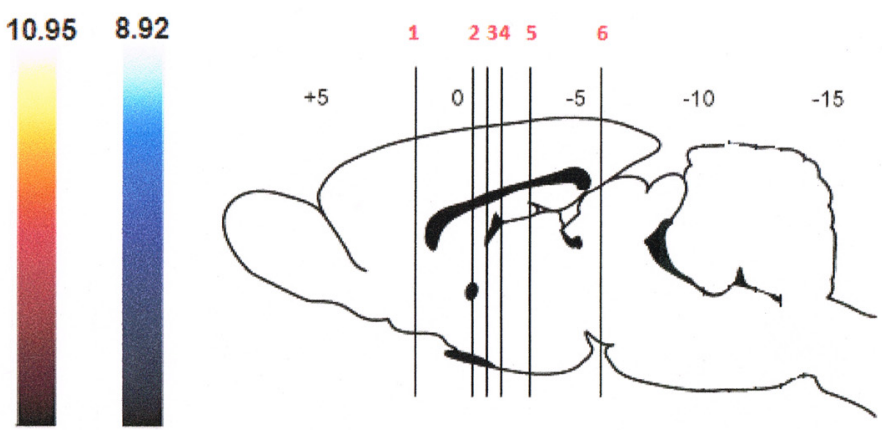

Figure 2. $\mu$ PET and statistical parametric mapping (SPM8) results from the ChR2 group coregistered to the Schweinhardt MRI template. Red, Stimulation $>$ Baseline (Excitation); Blue, Baseline $>$ Stimulation (Inhibition). $p<0.005 ; K_{\mathrm{e}}>100 ; T>5.72$. Location of coronal sections shown from sagittal view on the right, numbered respectively. Sagittal reference image on the right adapted to show location of corresponding numbered coronal plates (Paxinos and Watson, 2007). Regions labeled represent regions encompassed by the span of the respective cluster. Cg1, Cingulate gyrus, area 1; CPu, caudate-putamen; VP, ventral pallidum; $\$ 2$, secondary somatosensory cortex; Amyg, amygdala; RSA, retrosplenial cortex; dHP, dorsal hippocampus; st, stria terminalis.

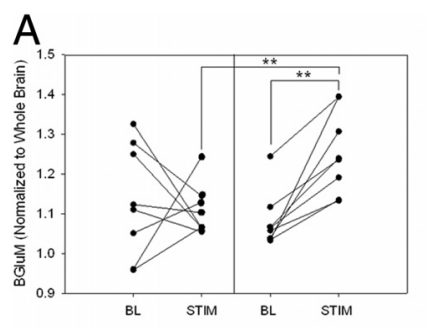

B

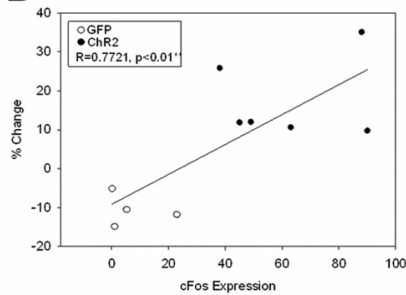

Figure 3. A, Individual metabolic values in NAc and correlation with CFOS. Brain glucose metabolism (BGluM) in the NAc during the baseline (BL) and stimulation (STIM) scans in GFP (left) and ChR2 (right) rats. A ROI was drawn around the SPM cluster in the NAc that was shown to be significantly activated following OGS in the ChR2 group, and activity in this ROl was normalized to whole-brain activity during baseline and stimulation for both groups of rats. Each dot represents a data value for one animal. All ChR2 rats had greater activity in the NAc in the stimulation scan compared with the baseline scan, and this increase between scans was statistically significant for the ChR2 group only $\left({ }^{* *} p<0.01\right)$. Additionally, ChR2 rats had greater BGluM in the NAC ROI during the stimulation scan compared with GFP rats (** $p<0.01) . \boldsymbol{B}$, Correlation between c-Fos expression following stimulation and percent change in BGluM from baseline to stimulation scans. There was a statistically significant positive association between c-Fos expression in the NAc following stimulation and percent change in BGluM in the NAc from baseline to stimulation scans $\left(r=0.7721,{ }^{* *} p<0.01\right)$.

regions of the default mode network or DMN (retrosplenial cortex and anterior cingulate gyrus), and in secondary motor cortex.

Our finding of increased glucose metabolism and c-Fos expression at the site of OGS - the NAc-is consistent with fMRI results reporting an increase in BOLD signal in the area of stimulation (for prior study it was the motor cortex) (Lee, 2012), as well as immunohistochemistry studies showing increased c-Fos expression at the site of stimulation (Adamantidis et al., 2010; Lobo et al., 2010). This indicates that OGS with ChR2 activates neurons in the region where the light is delivered. As predicted, we also observed increased metabolism (activation) in regions that are connected to the NAc; specifically, the hippocampus, caudate/putamen, amygdala, periaqueductal gray, globus pallidus, and ventral pallidum. This is consistent with fMRI studies showing BOLD signal increases in regions neuroanatomically connected to the site of stimulation (Lee et al., 2010; Lee, 2012).

Interestingly, we showed decreased metabolic activity in the retrosplenial cortex (posterior cingulate gyrus), anterior cingulate gyrus, and secondary motor cortex. Both the retrosplenial cortex and the anterior cingulate gyrus are part of the DMN that is deactivated (including decreases in glucose metabolism) when engaging in a task (Raichle and Snyder, 2007; Pfefferbaum et al., 2011). The clusters of inhibition that we observed following OGS
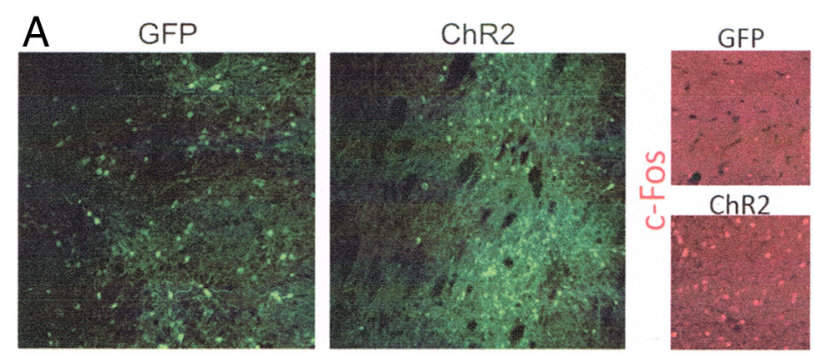

B

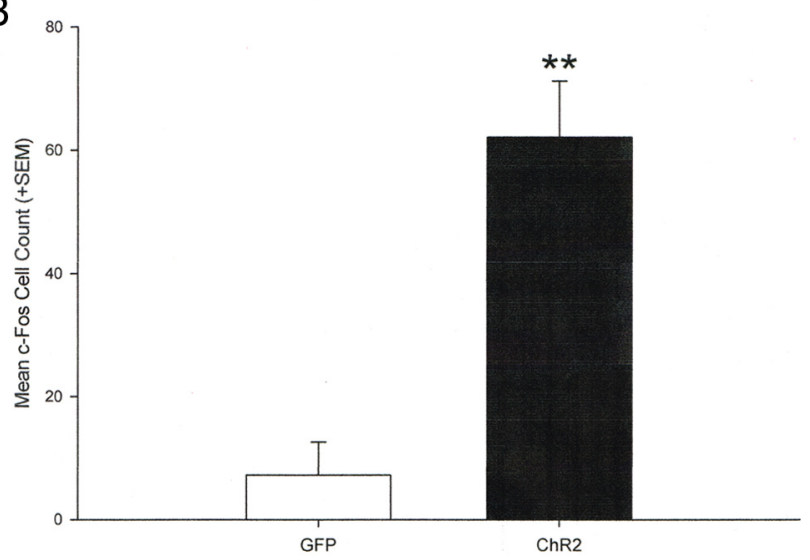

Figure 4. Rats were optogenetically stimulated in the NAc for $10 \mathrm{~min}$, then perfused $90 \mathrm{~min}$ later and their brains harvested. Immunohistochemistry was performed to visualize and quantify c-Fos expression in the nucleus accumbens following stimulation. $A$, Immunolabeling of c-Fos expression following optogenetic stimulation in GFP and ChR2 rats. B, Quantification of c-Fos expression following optogenetic stimulation in GFP and ChR2 rats. ChR2 rats showed significantly greater $c$-Fos expression compared with GFP rats $\left({ }^{* *} p<0.01\right)$.

of the NAc fall within the previously reported DMN of the rat brain (Upadhyay et al., 2011; Lu et al., 2012). Moreover, brain imaging studies indicate a correlation between markers of dopamine (DA) neurotransmission and deactivation of the DMN (Tomasi et al., 2009; Dang et al., 2012; Sambataro et al., 2013), which, in conjunction with our findings, suggests that NAc activation facilitates DMN inhibition.

A previous optogenetic fMRI study reported local excitatory responses (positive BOLD signal) following stimulation of the motor cortex with ChR2, flanked by inhibitory responses (negative BOLD signal) in lateral regions; however, no inhibitory responses in nonadjacent regions were reported (Lee et al., 2010). The NAc is comprised mostly of small spiny GABAergic neurons, which constitute the source of projections out of the NAc, but 
$\square$ GFP

ChR2
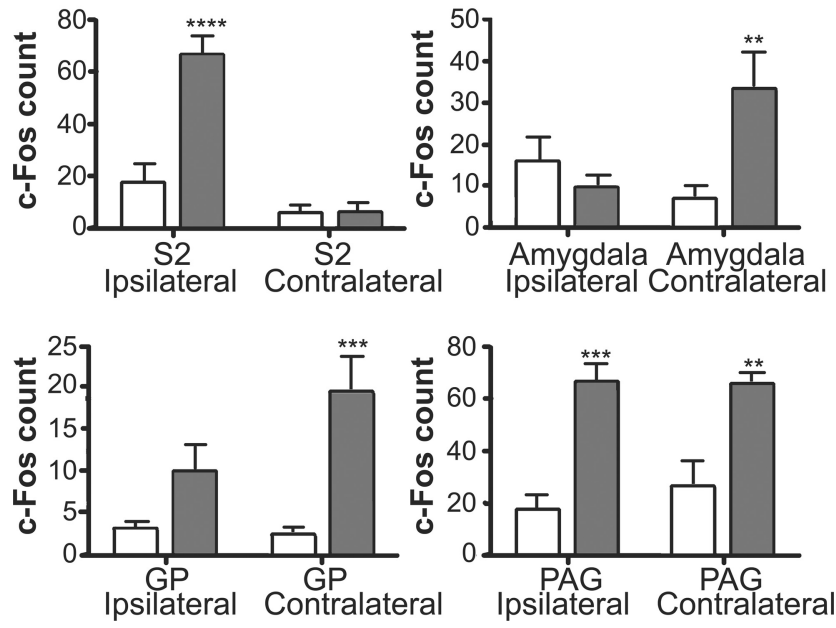

Figure 5. Quantification of c-Fos immunolabeling in regions found to be significantly activated (from $\mu$ PET results) following optogenetic stimulation of the NAc. Rats were optogenetically stimulated in the NAc for $10 \mathrm{~min}$, then perfused 90 min later and their brains harvested. Immunohistochemistry was performed to visualize and quantify c-Fos expression in the contralateral and ipsilateral secondary somatosensory cortex (S2), amygdala, GP, and PAG following stimulation. ChR2 rats showed significantly greater c-Fos expression compared with GFP rats in the ipsilateral S2 $\left(^{* * *} p<0.0001\right)$, contralateral amygdala $\left({ }^{* *} p<0.01\right)$, and GP $\left({ }^{* * *} p<0.001\right)$, as well as the ipsilateral $\left({ }^{* * *} p<0.001\right)$ and contralateral $\left({ }^{* *} p<0.01\right)$ PAG.

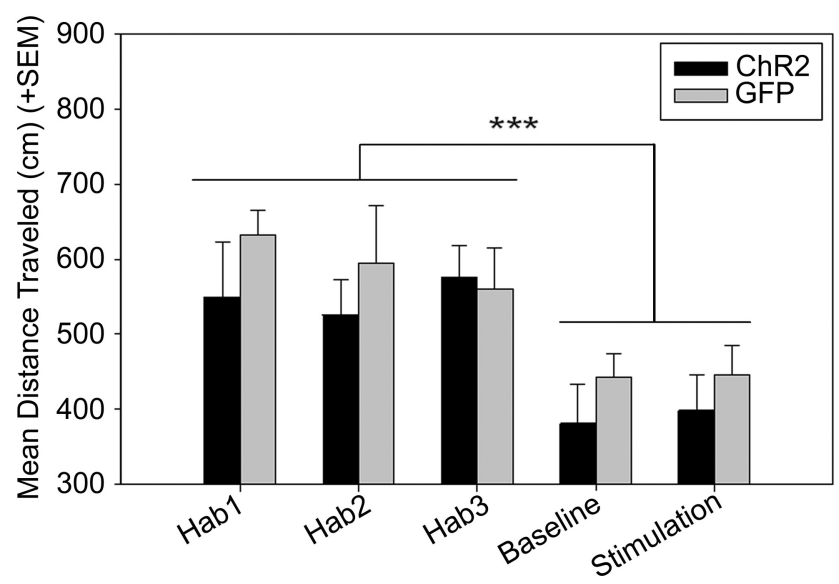

Figure 6. Locomotor activity during habituation and $\mu \mathrm{PET}$ scans. Locomotor activity was measured during three habituation (Hab) sessions, as well as during the period of FDG uptake immediately preceding baseline and stimulation $\mu$ PET scans. During all habituation and $\mu$ PET scan locomotor activity assessment periods, rats were attached to the optical fiber (light turned on for stimulation scan only) and locomotor activity was restricted by placement in a small holding cage. Rats were more active in the habituation sessions compared with the sessions before $\mu$ PET scans $\left({ }^{* *} p<0.05\right)$.

there are also acetylcholine interneurons that modulate activity of GABAergic neurons. Thus, increased metabolism in NAc is likely to reflect the activation of both sets of neurons, unless OGS also indirectly influences activity of afferent terminals into the region, in which case the increased metabolism could reflect increased glutamate release from corticostriatal, thalamo-striatal, or amygdo-striatal terminals or DA release from DA terminals (Kegeles et al., 2000; Fernandez et al., 2006; Eyjolfsson et al., 2011; Surmeier and Graybiel, 2012). Since the GABAergic neurons are the ones that project out of the NAc, the activation in connected regions is likely to reflect indirect circuit-level consequences of NAc activation. Studies that restrict the expression of the ChR2 to the NAc's two main types of projection neurons, those predominantly expressing DA D1 versus DA D2 receptors, are needed to clarify the circuitry underlying the metabolic changes seen with NAC stimulation. Note that Lee et al. (2010) used a vector that was designed to specifically drive the expression of $\mathrm{ChR} 2$ in $\mathrm{Ca}^{2+}$ / calmodulin-dependent protein kinase II $\alpha$ (CaMKII $\alpha$ )-expressing principal cortical neurons, which are excitatory, but not in GABAergic or other inhibitory cell types. However, we may have also stimulated cholinergic interneurons in the NAc; for while they constitute $<1 \%$ of NAc neurons (Rymar et al., 2004), their optogenetic activation and inhibition has been shown to modulate activity in other NAc neurons (Witten et al., 2010).

Downstream effects of OGS of the NAc seen in the amygdala and hippocampus are supported by known anatomical and functional connectivity that constitute the limbic system (Parkinson et al., 2000; Cardinal et al., 2002; Heidbreder and Groenewegen, 2003; Morgane et al., 2005). The activation of the basal ganglia (caudate/putamen, globus pallidus, and ventral pallidum) is also consistent with the basal ganglia modulating or being modulated by activity in the NAc, as well as the hypothesis that the NAc is the interface between limbic and motor systems (Groenewegen and Uylings, 2000; Heimer, 2003; Morgane et al., 2005; Postuma and Dagher, 2006). The activation of the PAG could reflect the functional loop between the NAc, PAG, and amygdala that underlies opioid-mediated antinociception (Ma and Han, 1991, 1992; Ma et al., 1992). Our results are also consistent with findings in the human brain of functional connectivity between the NAc and the amygdala, hippocampus, globus pallidus, caudate/putamen, anterior and posterior cingulate, and precuneus (retrosplenial cortex in the rat) (Cauda et al., 2011). Clinical studies have shown additional connectivity of the NAc with the orbitofrontal cortex, insula, and midbrain (Di Martino et al., 2008; Cauda et al., 2011); however, the lack of an observed effect in these regions in our study may reflect distinct connectivity patterns when the brain is studied during a resting state versus when it is studied during regional activation, as well as species and methodological differences.

In our study, NAc stimulation increased metabolism in the contralateral amygdala and hippocampus, which is consistent with a lateralization of NAc connections with these two other regions (Cauda et al., 2011); however, we did not see ipsilateral activation of these limbic regions. It is possible that this contralateral activation of downstream regions represents a compensatory mechanism for maintaining homeostasis. A similar effect has been demonstrated, such that unilateral stimulation of the subthalamic nucleus results in contralateral activation of downstream basal ganglia circuitry (Parent and Hazrati, 1995; Liu et al., 2002; Arai et al., 2008). We further explored c-Fos activation in some of the contralaterally activated regions, as well as control regions with ipsilateral and bilateral activation, following OGS of the NAc to determine whether these could be artifacts. Our findings from c-Fos immunolabeling corroborate our $\mu$ PET findings, showing increased expression in the contralateral amygdala and globus pallidus, ipsilateral secondary somatosensory cortex, and bilateral periaqueductal gray.

In our study, we also showed decreased metabolic activity in the motor cortex following stimulation of the NAc that might reflect the fact that during OGS the rats were placed in a small cage, which was used to prevent stimulation-induced locomotor hyperactivity. Thus, the restricted containment may have required that the animals inhibit motoric brain regions that otherwise would have been activated had they had the space to move. However, a previous study of unilateral OGS of the NAc also 
failed to increase basal locomotor activity even when mice were in a larger space (Lobo et al., 2010), which indicates that unilateral OGS of the NAc may be insufficient to elicit significant increases in locomotor activation. Previous studies have shown that locomotion-stimulating drugs are less effective when microinjected unilaterally into the NAc, compared with bilaterally (Jackson et al., 1975; Essman et al., 1993; Schildein et al., 1998). Additionally, the observed contralateral activation of downstream regions, previously proposed to be a compensatory mechanism, may be the neurobiological substrate through which the brain is homeostatically regulating behavioral output in response to unilateral stimulation of the NAc.

A limitation of our study is that since the vector we used equally infects all neurons, we cannot distinguish which neuronal cell type(s) drive the increases in metabolism in the NAc and its effects on downstream brain regions. As well, rats were fooddeprived overnight (12 h), according to standard protocols, before FDG PET scans to attain consistency in blood glucose levels as abnormal blood glucose levels interfere with FDG uptake (Fueger et al., 2006; Wong et al., 2011). While longer food deprivation $(24-48 \mathrm{~h})$ is known to be a stressor and to affect behavioral sensitivity to both natural and food rewards (Levine et al., 1995; Shalev et al., 2003a,b), it does not affect c-Fos immunoreactivity in the NAc or other regions of the reward pathway (Shalev et al., 2003a). This may be less of a concern in the present study as food deprivation was brief ( $12 \mathrm{~h})$. Last, although OGS-induced motor activation could have been a potential confound, this is unlikely to be the case since there were no differences in locomotor activation between the GFP and ChR2 rats during the stimulation session.

This study shows that ChR2-mediated OGS of the NAc results in activation of the NAc (as measured by both glucose metabolism and c-Fos expression), in addition to activation and inhibition of downstream projection regions. These results also provide evidence of the feasibility of using $\mu$ PET with FDG in conjunction with OGS to map connectivity in the awake, behaving rat brain.

\section{References}

Adamantidis A, Carter MC, de Lecea L (2010) Optogenetic deconstruction of sleep-wake circuitry in the brain. Front Mol Neurosci 2:31. Medline

Apostolova I, Block S, Buchert R, Osen B, Conradi M, Tabrizian S, Gensichen S, Schröder-Hartwig K, Fricke S, Rufer M, Weiss A, Hand I, Clausen M, Obrocki J (2010) Effects of behavioral therapy or pharmacotherapy on brain glucose metabolism in subjects with obsessive-compulsive disorder as assessed by brain FDG PET. Psychiatry Res 184:105-116. CrossRef Medline

Arai N, Yokochi F, Ohnishi T, Momose T, Okiyama R, Taniguchi M, Takahashi H, Matsuda H, Ugawa Y (2008) Mechanisms of unilateral STNDBS in patients with Parkinson's disease: a PET study. J Neurol 255: 1236-1243. CrossRef Medline

Boyden ES, Zhang F, Bamberg E, Nagel G, Deisseroth K (2005) Millisecondtimescale, genetically targeted optical control of neural activity. Nat Neurosci 8:1263-1268. CrossRef Medline

Cardin JA, Carlén M, Meletis K, Knoblich U, Zhang F, Deisseroth K, Tsai LH, Moore CI (2010) Targeted optogenetic stimulation and recording of neurons in vivo using cell-type-specific expression of Channelrhodopsin-2. Nat Protoc 5:247-254. CrossRef Medline

Cardinal RN, Parkinson JA, Hall J, Everitt BJ (2002) Emotion and motivation: the role of the amygdala, ventral striatum, and prefrontal cortex. Neurosci Biobehav Rev 26:321-352. CrossRef Medline

Cauda F, Cavanna AE, D'agata F, Sacco K, Duca S, Geminiani GC (2011) Functional connectivity and coactivation of the nucleus accumbens: a combined functional connectivity and structure-based meta-analysis. J Cogn Neurosci 23:2864-2877. CrossRef Medline

Dang LC, Donde A, Madison C, O’Neil JP, Jagust WJ (2012) Striatal dopa- mine influences the default mode network to affect shifting between object features. J Cogn Neurosci 24:1960-1970. CrossRef Medline

Di Martino A, Scheres A, Margulies DS, Kelly AM, Uddin LQ, Shehzad Z, Biswal B, Walters JR, Castellanos FX, Milham MP (2008) Functional connectivity of human striatum: a resting state FMRI study. Cereb Cortex 18:2735-2747. CrossRef Medline

Essman WD, McGonigle P, Lucki I (1993) Anatomical differentiation within the nucleus accumbens of the locomotor stimulatory actions of selective dopamine agonists and $d$-amphetamine. Psychopharmacology 112:233-241. CrossRef Medline

Eyjolfsson EM, Nilsen LH, Kondziella D, Brenner E, Håberg A, Sonnewald U (2011) Altered 13C glucose metabolism in the cortico-striato-thalamocortical loop in the MK-801 rat model of schizophrenia. J Cereb Blood Flow Metab 31:976-985. CrossRef Medline

Fernandez E, Schiappa R, Girault JA, Le Novère N (2006) DARPP-32 is a robust integrator of dopamine and glutamate signals. PLoS Comput Biol 2:e176. CrossRef Medline

Fueger BJ, Czernin J, Hildebrandt I, Tran C, Halpern BS, Stout D, Phelps ME, Weber WA (2006) Impact of animal handling on the results of 18F-FDG PET studies in mice. J Nucl Med 47:999-1006. Medline

Groenewegen HJ, Uylings HB (2000) The prefrontal cortex and the integration of sensory, limbic and autonomic information. Prog Brain Res 126: 3-28. CrossRef Medline

Heidbreder CA, Groenewegen HJ (2003) The medial prefrontal cortex in the rat: evidence for a dorso-ventral distinction based upon functional and anatomical characteristics. Neurosci Biobehav Rev 27:555-579. CrossRef Medline

Heimer L (2003) A new anatomical framework for neuropsychiatric disorders and drug abuse. Am J Psychiatry 160:1726-1739. CrossRef Medline

Heinke W, Koelsch S (2005) The effects of anesthetics on brain activity and cognitive function. Curr Opin Anaesthesiol 18:625-631. CrossRef Medline

Jackson DM, Andén NE, Dahlström A (1975) A functional effect of dopamine in the nucleus accumbens and in some other dopamine-rich parts of the rat brain. Psychopharmacologia 45:139-149. CrossRef Medline

Kahn I, Desai M, Knoblich U, Bernstein J, Henninger M, Graybiel AM, Boyden ES, Buckner RL, Moore CI (2011) Characterization of the functional MRI response temporal linearity via optical control of neocortical pyramidal neurons. J Neurosci 31:15086-15091. CrossRef Medline

Kegeles LS, Abi-Dargham A, Zea-Ponce Y, Rodenhiser-Hill J, Mann JJ, Van Heertum RL, Cooper TB, Carlsson A, Laruelle M (2000) Modulation of amphetamine-induced striatal dopamine release by ketamine in humans: implications for schizophrenia. Biol Psychiatry 48:627-640. CrossRef Medline

Lee JH (2011) Tracing activity across the whole brain neural network with optogenetic functional magnetic resonance imaging. Front Neuroinform 5:21. Medline

Lee JH (2012) Informing brain connectivity with optogenetic functional magnetic resonance imaging. Neuroimage 62:2244-2249. CrossRef Medline

Lee JH, Durand R, Gradinaru V, Zhang F, Goshen I, Kim DS, Fenno LE, Ramakrishnan C, Deisseroth K (2010) Global and local fMRI signals driven by neurons defined optogenetically by type and wiring. Nature 465:788-792. CrossRef Medline

Levine AS, Weldon DT, Grace M, Cleary JP, Billington CJ (1995) Naloxone blocks that portion of feeding driven by sweet taste in food-restricted rats. Am J Physiol 268:R248-R252. Medline

Liu X, Ford-Dunn HL, Hayward GN, Nandi D, Miall RC, Aziz TZ, Stein JF (2002) The oscillatory activity in the Parkinsonian subthalamic nucleus investigated using the macro-electrodes for deep brain stimulation. Clin Neurophysiol 113:1667-1672. CrossRef Medline

Lobo MK, Covington HE 3rd, Chaudhury D, Friedman AK, Sun H, DamezWerno D, Dietz DM, Zaman S, Koo JW, Kennedy PJ, Mouzon E, Mogri M, Neve RL, Deisseroth K, Han MH, Nestler EJ (2010) Cell type-specific loss of BDNF signaling mimics optogenetic control of cocaine reward. Science 330:385-390. CrossRef Medline

Lu H, Zou Q, Gu H, Raichle ME, Stein EA, Yang Y (2012) Rat brains also have a default mode network. Proc Natl Acad Sci U S A 109:3979-3984. CrossRef Medline

Ma QP, Han JS (1991) Naloxone blocks the release of opioid peptides in periaqueductal gray and $\mathrm{N}$. accumbens induced by intra-amygdaloid injection of morphine. Peptides 12:1235-1238. CrossRef Medline 
Ma QP, Han JS (1992) Naloxone blocks opioid peptide release in periaqueductal gray and amygdala elicited by morphine injected into N. accumbens. Peptides 13:261-265. CrossRef Medline

Ma QP, Shi YS, Han JS (1992) Naloxone blocks opioid peptide release in N. accumbens and amygdala elicited by morphine injected into periaqueductal gray. Brain Res Bull 28:351-354. CrossRef Medline

Michaelides M, Thanos PK, Kim R, Cho J, Ananth M, Wang GJ, Volkow ND (2012) PET imaging predicts future body weight and cocaine preference. Neuroimage 59:1508-1513. CrossRef Medline

Morgane PJ, Galler JR, Mokler DJ (2005) A review of systems and networks of the limbic forebrain/limbic midbrain. Prog Neurobiol 75:143-160. CrossRef Medline

Parent A, Hazrati LN (1995) Functional anatomy of the basal ganglia. II. The place of subthalamic nucleus and external pallidum in basal ganglia circuitry. Brain Res Brain Res Rev 20:128-154. CrossRef Medline

Parkinson JA, Willoughby PJ, Robbins TW, Everitt BJ (2000) Disconnection of the anterior cingulate cortex and nucleus accumbens core impairs Pavlovian approach behavior: further evidence for limbic cortical-ventral striatopallidal systems. Behav Neurosci 114:42-63. CrossRef Medline

Pascau J, Gispert JD, Michaelides M, Thanos PK, Volkow ND, Vaquero JJ, Soto-Montenegro ML, Desco M (2009) Automated method for smallanimal PET image registration with intrinsic validation. Mol Imaging Biol 11:107-113. CrossRef Medline

Paxinos G, Watson C (2007) The rat brain in stereotaxic coordinates, Ed 6. Amsterdam: Elsevier.

Pfefferbaum A, Chanraud S, Pitel AL, Müller-Oehring E, Shankaranarayanan A, Alsop DC, Rohlfing T, Sullivan EV (2011) Cerebral blood flow in posterior cortical nodes of the default mode network decreases with task engagement but remains higher than in most brain regions. Cereb Cortex 21:233-244. CrossRef Medline

Postuma RB, Dagher A (2006) Basal ganglia functional connectivity based on a meta-analysis of 126 positron emission tomography and functional magnetic resonance imaging publications. Cereb Cortex 16:1508-1521. Medline

Qiu M, Ramani R, Swetye M, Constable RT (2008) Spatial nonuniformity of the resting CBF and BOLD responses to sevoflurane: in vivo study of normal human subjects with magnetic resonance imaging. Hum Brain Mapp 29:1390-1399. CrossRef Medline

Raichle ME, Snyder AZ (2007) A default mode of brain function: a brief history of an evolving idea. Neuroimage 37:1083-1090. CrossRef Medline

Rice O, Saintvictor S, Michaelides M, Thanos P, Gatley SJ (2006) MicroPET investigation of chronic long-term neurotoxicity from heavy ion irradiation. AAPS J 8:E508-E514. CrossRef Medline

Rymar VV, Sasseville R, Luk KC, Sadikot AF (2004) Neurogenesis and stereological morphometry of calretinin-immunoreactive GABAergic interneurons of the neostriatum. J Comp Neurol 469:325-339. CrossRef Medline

Sambataro F, Fazio L, Taurisano P, Gelao B, Porcelli A, Mancini M, Sinibaldi L, Ursini G, Masellis R, Caforio G, Di Giorgio A, Niccoli-Asabella A, Popolizio T, Blasi G, Bertolino A (2013) DRD2 genotype-based variation of default mode network activity and of its relationship with striatal DAT binding. Schizophr Bull 39:206-216. CrossRef Medline

Schildein S, Agmo A, Huston JP, Schwarting RKW (1998) Intraaccumbens injections of substance $\mathrm{P}$, morphine and amphetamine: effects on conditioned place preference and behavioral activity. Brain Res 790:185-194. CrossRef Medline

Shalev U, Robarts P, Shaham Y, Morales M (2003a) Selective induction of c-Fos immunoreactivity in the prelimbic cortex during reinstatement of heroin seeking induced by acute food deprivation in rats. Behav Brain Res 145:79-88. CrossRef Medline

Shalev U, Marinelli M, Baumann MH, Piazza PV, Shaham Y (2003b) The role of corticosterone in food deprivation-induced reinstatement of cocaine seeking in the rat. Psychopharmacology 168:170-176. CrossRef Medline

Sobrado M, Delgado M, Fernández-Valle E, García-García L, Torres M, Sánchez-Prieto J, Vivancos J, Manzanares R, Moro MA, Pozo MA, Lizasoain I (2011) Longitudinal studies of ischemic penumbra by using $18 \mathrm{~F}$ FDG PET and MRI techniques in permanent and transient focal cerebral ischemia in rats. Neuroimage 57:45-54. CrossRef Medline

Stover JF, Sakowitz OW, Kroppenstedt SN, Thomale UW, Kempski OS, Flugge G, Unterberg AW (2004) Differential effects of prolonged isoflurane anesthesia on plasma, extracellular, and CSF glutamate, neuronal activity, 125I-Mk801 NMDA receptor binding, and brain edema in traumatic brain-injured rats. Acta Neurochir (Wien) 146:819-830.

Surmeier DJ, Graybiel AM (2012) A feud that wasn't: acetylcholine evokes dopamine release in the striatum. Neuron 75:1-3. CrossRef Medline

Thanos PK, Michaelides M, Benveniste H, Wang GJ, Volkow ND (2008a) The effects of cocaine on regional brain glucose metabolism is attenuated in dopamine transporter knockout mice. Synapse 62:319-324. CrossRef Medline

Thanos PK, Michaelides M, Gispert JD, Pascau J, Soto-Montenegro ML, Desco M, Wang R, Wang GJ, Volkow ND (2008b) Differences in response to food stimuli in a rat model of obesity: in-vivo assessment of brain glucose metabolism. Int J Obesity 32:1171-1179. CrossRef

Tomasi D, Volkow ND, Wang R, Telang F, Wang GJ, Chang L, Ernst T, Fowler JS (2009) Dopamine transporters in striatum correlate with deactivation in the default mode network during visuospatial attention. PLoS One 4:e6102. CrossRef Medline

Tsurugizawa T, Uematsu A, Uneyama H, Torii K (2010) Effects of isoflurane and alpha-chloralose anesthesia on BOLD fMRI responses to ingested L-glutamate in rats. Neuroscience 165:244-251. CrossRef Medline

Upadhyay J, Baker SJ, Chandran P, Miller L, Lee Y, Marek GJ, Sakoglu U, Chin CL, Luo F, Fox GB, Day M (2011) Default-mode-like network activation in awake rodents. PLoS One 6:e27839. CrossRef Medline

Volkow ND, Wang GJ, Telang F, Fowler JS, Goldstein RZ, Alia-Klein N, Logan J, Wong C, Thanos PK, Ma Y, Pradhan K (2009) Inverse association between BMI and prefrontal metabolic activity in healthy adults. Obesity 17:60-65. CrossRef Medline

Volkow ND, Tomasi D, Wang GJ, Fowler JS, Telang F, Goldstein RZ, AliaKlein N, Wong C (2011) Reduced metabolism in brain "control networks" following cocaine-cues exposure in female cocaine abusers. PLoS One 6:e16573. CrossRef Medline

Wang GJ, Volkow ND, Telang F, Jayne M, Ma Y, Pradhan K, Zhu W, Wong CT, Thanos PK, Geliebter A, Biegon A, Fowler JS (2009) Evidence of gender differences in the ability to inhibit brain activation elicited by food stimulation. Proc Natl Acad Sci U S A 106:1249-1254. CrossRef Medline

Witten IB, Lin SC, Brodsky M, Prakash R, Diester I, Anikeeva P, Gradinaru V, Ramakrishnan C, Deisseroth K (2010) Cholinergic interneurons control local circuit activity and cocaine conditioning. Science 330:1677-1681. CrossRef Medline

Wong KP, Sha W, Zhang X, Huang SC (2011) Effects of administration route, dietary condition, and blood glucose level on kinetics and uptake of 18F-FDG in mice. J Nucl Med 52:800-807. CrossRef Medline

Zhang F, Gradinaru V, Adamantidis AR, Durand R, Airan RD, de Lecea L, Deisseroth K (2010) Optogenetic interrogation of neural circuits: technology for probing mammalian brain structures. Nat Protoc 5:439-456. CrossRef Medline 